\title{
ESTUDO COMPARATIVO DO EFEITO FUNGICIDA DO ÓLEO COMERCIAL SAFETEAM E DO TRATAMENTO DE ULTRASSOM EM FLUIDOS DE CORTE
}

\author{
COMPARATIVE STUDY OF THE FUNGICIDE EFFECT OF SAFETEAM \\ COMMERCIAL OIL AND ULTRASOUND TREATMENT IN CUTTING FLUIDS \\ Rachele Marcon Nicoliello ${ }^{1}$ \\ Cassia Fernanda de Oliveira Barbosa ${ }^{2}$ \\ Milena Chanes de Souza ${ }^{3}$ \\ Sonia Khouri ${ }^{4}$ \\ Evelyn Alves Nunes Simonetti ${ }^{5}$
}

Resumo: O setor de Usinagem utiliza fluidos de corte de base vegetal em suas máquinas-ferramenta por serem mais sustentáveis, porém sua composição química os torna mais susceptíveis à degradação. $O$ principal objetivo deste trabalho foi avaliar dois tratamentos para o controle microbiológico em fluidos de corte: extrato vegetal Safeteam (tratamento químico) e ultrassom (tratamento físico). De acordo com o histórico de degradação dos fluidos de corte do Centro de Competência em Manufatura (CCM) e dados da literatura, identificou-se que o gênero Penicillium sp aparece com maior frequência. Para avaliar a eficiência dos tratamentos, utilizou-se fluido de corte de base vegetal (sem biocida) e cepas de Penicillium oxalicum. No primeiro tratamento, utilizou-se a Concentração Mínima Inibitória (CMI) de 5\% do óleo comercial Safeteam, utilizando o método de profundidade. No segundo tratamento, com ultrassom, utilizou-se $100 \mathrm{~mL}$ de amostra de fluido de corte (90\% de água e 10\% de concentrado) para cada parâmetro (variando 2 tempos e 3 potências). Como resultado, o extrato vegetal na CMI de 5\% apresentou uma redução de $100 \%$ do número de Unidades Formadoras de Colônias (UFCs) e o ultrassom uma redução significativa das UFCs, que não foi quantificada, já que, na leitura inicial, a quantidade de colônias foi incontável. Permitindo concluir que ambas as técnicas apresentaram resultados positivos para o controle do bolor Penicillium oxalicum em fluidos de corte.

Palavras-chave: fluidos de corte; extrato vegetal; ultrassom; efeito fungicida.

Abstract: The machining industry uses vegetable cutting fluids in their machine tools because they are more sustainable, but its chemical composition becomes more susceptible to degradation. The machining industry uses vegetable based cutting fluids in their machine-tools for they are more sustainable, however their chemical composition makes them more susceptible to degradation. The aim of this study was to evaluate two treatments to the microbiological control in cutting fluids: Safeteam plant extract (chemical treatment) and ultrasound (physical treatment). According to the cutting fluids historic degradation of the Centro de Competência em Manufatura (CCM) and literature data, it has been identified that the genus Penicillium sp appears with the most frequency. To evaluate the treatments effectiveness a cutting vegetable based fluid (no biocide) and Penicillium oxalicum strains were used. In the first treatment the Minimum Inhibitory Concentration (CMI) of 5\% of the comercial Safeteam oil was applied by using the depth method. In the second treatment, with ultrasound, $100 \mathrm{ml}$ cutting fluid sample $(90 \%$ of water and $10 \%$ of concentrate) was used for each parameter (varying 2 times and 3 powers). As a result the plant extract at the 5\% MIC presented a 100\% reduction of the Colony Forming Units (CFU) and the ultrasound

\footnotetext{
${ }^{1}$ Graduanda em Biomedicina - Universidade do Vale do Paraíba - UNIVAP, Brasil. E-mail: rachele.nicoliello@hotmail.com.

${ }^{2}$ Graduanda em Biomedicina - Universidade do Vale do Paraíba - UNIVAP, Brasil. E-mail:

cassia.barbosa93@hotmail.com.

${ }^{3}$ Mestre em Materiais e Processos de Fabricação pelo Instituto Tecnológico de Aeronáutica - ITA, Brasil. Email:milena@ita.br.

${ }^{4}$ Doutora em Microbiologia pela Universidade de São Paulo - USP. Professora Titular das disciplinas de Microbiologia na Universidade do Vale do Paraíba - UNIVAP, Brasil. E-mail: soniak@univap.br.

${ }^{5}$ Doutora em Engenharia Aeronáutica e Mecânica. Docente do Ensino Básico Técnico e Tecnológico (EBTT) do Instituto Federal de São Paulo, Brasil. E-mail: evelynalvesnunes@yahoo.com.br.
} 
a significant reduction of the CFU. Thus, allowing to conclude that both tecniques presented positive results against the mold Penicilium oxalicum in cutting fluids.

Keywords: cutting fluids; vegetable extract; ultrasound; fungicidal effect.

\section{INTRODUÇÃO}

O setor industrial metal-mecânico atua na produção e transformação de diversas ligas metálicas (ferro, alumínio, aço, entre outros), polímeros e compósitos. Essa indústria compreende diversos setores, um deles é o de Usinagem, no qual máquinas conhecidas como máquinas-ferramentas cortam e modelam diversos tipos de materiais para a manufatura de peças (SILVA et. al, 2014). Com a finalidade de aumentar a vida útil da máquina-ferramenta, garantir maior rendimento na produção e melhores acabamentos superficiais, são empregados lubrificantes durante o processo de corte, denominados fluidos de corte. Estes agem por intermédio da minimização do atrito entre a ferramenta e o cavaco, no controle da temperatura, e na remoção do material particulado, evitando o superaquecimento e a corrosão de máquinasferramentas e de peças (BIANCHI et al., 2007).

A proliferação de micro-organismos leva a perda de propriedades do fluido, diminuindo o seu desempenho e causando mau odor (GOMES, 2005). No Brasil e no mundo, investigações sobre o uso de produtos naturais com atividade antimicrobiana e tratamentos alternativos para aumentar a vida útil dos fluidos de corte têm aumentado significativamente nos últimos anos.

\subsection{Tratamento Químico}

O tratamento químico, como, por exemplo, adição de biocidas aos fluidos de corte devem inibir o crescimento microbiano (LUCCHESI, 2006). De acordo com Freire, Morra e Knudsen (2003), o uso de produtos químicos sempre ofereceu efeito antimicrobiano imediato, mas consequências imprevisíveis para o futuro. A alta toxidez e os efeitos residuais nocivos foram percebidos depois de décadas de utilização, que. aliado à resistência bacteriana que esses produtos causam. tem estimulado a pesquisa por novos produtos que não sejam agressivos ao meio ambiente.

Por serem provenientes de recursos renoáveis e uma alternativa mais sustentável, quando comparados aos produtos derivados do petróleo, os extratos e óleos essenciais de plantas têm se mostrado uma opção eficiente no controle do crescimento de uma ampla variedade de micro-organismos, incluindo fungos filamentosos, leveduras e bactérias (DUARTE, 2006). Os princípios ativos utilizados como biocidas naturais são extraídos principalmente do óleo das sementes, frutos, folhas e caules de espécies vegetais.

Os óleos essenciais são misturas complexas de compostos voláteis, geralmente, odoríferos e líquidos em temperatura ambiente, responsáveis por funções, como 
atração de polinizadores, proteção da planta contra altas temperaturas, dentre outras (DOURADO et. al, 2014). No Brasil, existem variados estudos e publicações referentes aos óleos essenciais com atividade antimicrobiana, porém ainda existem poucas patentes nacionais na área.

Segundo Caetano e Madaleno (2011), é comumente relatada a poderosa atividade antimicrobiana do extrato vegetal de Pomelo. A presença de flavonoides, esteróis e fenóis, em sua composição química, promovem o rompimento da membrana microbiana. Essa atividade já foi testada tanto para bactérias quanto para cepas fúngicas, sendo eficaz para ambas.

O Pomelo, também conhecido como toranja, pertence à família Rutaceae, gênero Citrus, e pode ser considerado um eficiente biocida natural por apresentar um amplo espectro antimicrobiano, além de necessitar de baixas concentrações para atingir o objetivo de inibir os micro-organismos (MONSELL, 2009). O principal componente do extrato da semente de Pomelo é o difenol-hidroxibenzeno que, por ser um composto iônico, penetra, facilmente, pela membrana plasmática, provocando o rompimento da membrana bacteriana e liberação do conteúdo citoplasmático (CAETANO; MADALENO, 2011).

Esse produto está em processo de patente, vem sendo patenteado, e seu uso já é de interesse da indústria como método alternativo ou em combinação com outros métodos para o controle de contaminação microbiológica (SILVA, 2007). A eficácia do extrato vegetal de Pomelo já foi testada na área farmacêutica, em processos de fermentação alcoólica; no entanto, não há nada descrito sobre a ação desse extrato em fluidos de corte. Os biocidas mais utilizados nos fluidos de corte são as isotiazolinonas, a triazina, o piritionato de sódio, o bronopol, entre outros. Todos têm como alvo promover a lise da membrana, parede celular ou atuar na coagulação de enzimas no citoplasma (CAPELLETTI, 2006).

\subsection{Tratamento Físico}

O equipamento de ultrassom para tratar líquidos possui cristais piezelétricos acoplados em um recipiente metálico (titânio), que promove ondas sonoras no líquido a ser testado, a fim de desnaturar células microbianas. Experiências mostraram a eficiência da ação germicida do ultrassom a uma frequência de $26.000 \mathrm{~Hz}$, aplicada em suspensões aquosas de bactérias (QUARESMA, 2013).

O ultrassom tem como princípio ativo ondas mecânicas com frequência acima de $20 \mathrm{KHz}$, capazes de formar bolhas de cavitação que têm energia suficiente para causar danos na estrutura da célula microbiana (parede/membrana celular) e posterior morte dessa célula (QUARESMA, 2013). E, de acordo com Suslick (1990) apud Quaresma (2013), o efeito do ultrassom na área biológica ocorre devido à sua potência acústica, capaz de distorcer partículas intracelulares ou mesmo células. $O$ 
ultrassom possui o efeito biofísico da cavitação, um dos principais mecanismos de atividade germicida em meio líquido, associado ao aquecimento localizado e a formação de radicais livres (QUARESMA, 2013).

Segundo Caliari, Soares Júnior e Gomes (2004), o efeito do tempo foi mais significativo que a potência utilizada no tratamento com ultrassom de caldo de cana contaminado por bactéria Leuconostoc mesenteroides. Testou-se um tempo de 21 minutos a $20 \mathrm{~W}$, em comparação a 3 minutos a 100W, onde houve pequenas reduções na contaminação, no tempo maior de tratamento.

A tecnologia do ultrassom se tornou mais comum e econômica nos dias atuais, o que comprova que a técnica é uma alternativa viável para controle do crescimento microbiano (QUARESMA, 2013). Esse tratamento com ultrassom tem sido usado industrialmente para limpar, misturar e acelerar processos químicos e, dentre eles, pode ser usado como um método potencial de inativação microbiana (NOVELLINE, 1997).

\section{OBJETIVO}

O presente estudo tem como objetivo avaliar a eficiência de dois tratamentos para o controle fúngico em fluidos de corte: o extrato vegetal de Pomelo como fungicida (tratamento químico) e o ultrassom (tratamento físico). Buscando alternativas mais sustentáveis para redução de contaminação microbiológica em fluidos de corte.

\section{MATERIAIS E MÉTODOS}

Com um levantamento histórico dos micro-organismos presentes nos fluidos de corte de três máquinas-ferramentas do laboratório Centro de Competência em Manufatura - CCM, do Instituto Tecnológico de Aeronáutica - ITA e dados da literatura, fez-se a identificação dos micro-organismos que se desenvolvem com maior frequência nos lubrificantes. Notou-se que tanto a literatura quanto o histórico do CCM indicaram que os bolores do gênero Penicillium $s p$ se desenvolvem com maior frequência, Figura 1. As espécies Fusarium sp., Penicillium sp. e Candida sp. também foram identificadas por THOMÉ et. al (2007). 
Figura 1: Gêneros e espécies de micro-organismos identificados no CCM e na literatura.

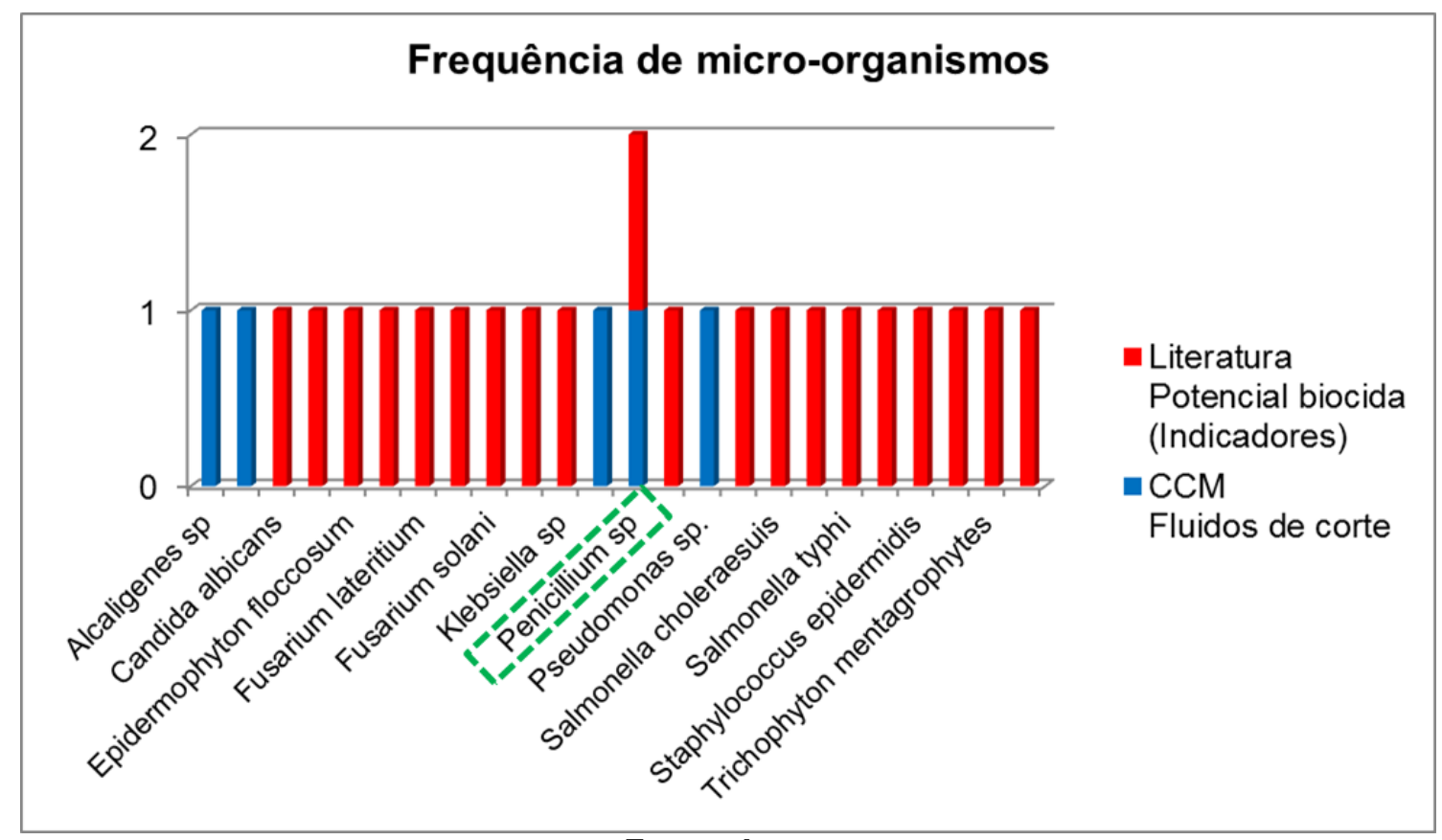

Fonte: Autor.

Com a identificação do micro-organimo a ser avaliado Penicillium sp., adquiriu-se cepas padrão de Penicillium oxalicum para a contaminação induzida do fluido de corte. O fluido de corte, base éster vegetal, utilizado no estudo foi preparado em laboratório pela empresa Houghton. O fluxograma dos ensaios, para avaliação da eficiência do tratamento químico e físico, está descrito na Figura 2.

O concentrado do fluido de corte da Houghton ficou armazenado em uma caixa térmica com gelo, durante o transporte do CCM até a Universidade do Vale do Paraíba (UNIVAP). E, na UNIVAP, manteve-se na geladeira em $4^{\circ} \mathrm{C}$, a fim de manter a integridade da amostra preparada sem biocidas. 
Figura 2: Fluxograma de ensaios para avaliar o potencial dos tratamentos químico e físico.

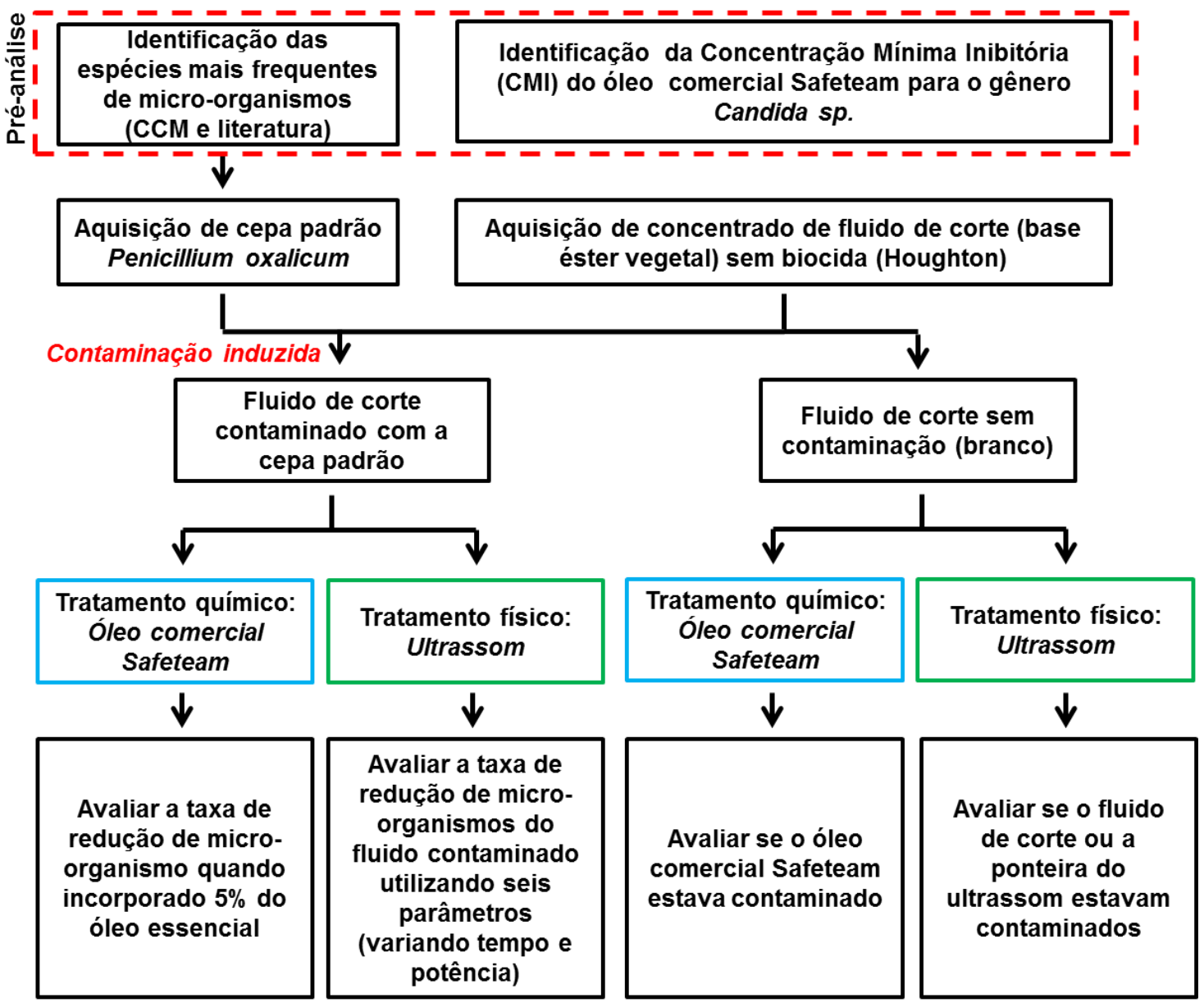

Fonte: Autor.

\subsection{Tratamento Químico - Óleo essencial comercial Safeteam}

Como referência da Concentração Mínima Inibitória $(\mathrm{CMI})$ a ser utilizada do extrato vegetal de pomelo, comercialmente denominado de Safetem, utilizou-se de dados obtidos em ensaios anteriores, realizados pela técnica de difusão em ágar com o extrato vegetal sobre as cepas ATCC 10231 e clínica P2CV do gênero Candida sp.

Partindo do princípio que a CMI do Safetem é 5\%, para o Penicillium oxalicum, seguiu-se o método de contagem em placa (meio Plate Count Agar), descrito na Farmacopéia $5^{\text {a }}$ edição volume 1 . Este descreve o método de profundidade, onde se adiciona $1 \mathrm{~mL}$ da amostra pura e diluições em placas de Petri e verte-se, separadamente, $20 \mathrm{~mL}$ de Potato Dextrose Ágar, mantidos em banho-maria a $45^{\circ} \mathrm{C}$, sobre cada placa.

Os ensaios realizados foram divididos em 4 grupos, a fim de uma análise comparativa:

- Grupo 1: avaliou-se apenas o fluido de corte sem biocida para verificar se já não estava contaminado; 
- Grupo 2: avaliou-se o fluido contaminado com o inóculo do fungo Penicillium oxalicum;

- Grupo 3: avaliou-se o fluido sem contaminação com a adição do extrato vegetal comercial na concentração de 5\%;

- Grupo 4: avaliou-se o fluido contaminado com o inóculo do fungo Penicillium oxalicum com a adição do extrato vegetal comercial na concentração de 5\%.

No grupo 1 , foram incubadas duas placas, uma a $37^{\circ} \mathrm{C}$, para pesquisa de leveduras e a outra a $25^{\circ} \mathrm{C}$, para pesquisa de bolores. Nos grupos 2,3 e 4 , todas as placas foram incubadas a $25^{\circ} \mathrm{C}$, para pesquisa de bolores. Então, foram utilizadas quatro placas de Petri para cada grupo de análise, a uma temperatura de incubação de $25^{\circ} \mathrm{C}$, uma placa para amostra pura, e outras três com diluições seriadas de 1:10 a 1:1000, mas os testes foram realizados em duplicata; por esse motivo, foram utilizadas oito placas para cada grupo, assim, ao todo, vinte e quatro placas e $480 \mathrm{~mL}$ de meio de cultura, sendo $20 \mathrm{~mL}$ em cada placa.

\subsection{Tratamento Físico - Ultrassom}

Para o método de ultrassom, foram avaliados $100 \mathrm{~mL}$ de amostra de fluido de corte (10\% de concentrado para $90 \%$ de água) para cada condição de tratamento, variando tempo e potência do equipa. Utilizou-se o método pulsado do ultrassom (90\%), variando dois tempos (15 e 30 minutos) e três potências (144, 108 e 72 Watts), conforme tabela 1.

Tabela 1 - Condições de tratamento dos fluidos de corte com ultrassom.

\begin{tabular}{cccc}
\hline $\begin{array}{c}\text { Condiçöes de } \\
\text { tratamento }\end{array}$ & $\begin{array}{c}\text { Potência } \\
\mathbf{1 4 4} \mathrm{W} \\
(\mathbf{1 0 0 \% )}\end{array}$ & $\begin{array}{c}\text { Potência } \\
\mathbf{1 0 8} \mathrm{W} \\
\mathbf{( 7 5 \% )}\end{array}$ & $\begin{array}{c}\text { Potência } \\
\mathbf{7 2} \mathrm{W} \\
\mathbf{( 5 0 \% )}\end{array}$ \\
\hline $\begin{array}{c}\text { Tempo } \\
\text { (30 Minutos) } \\
\begin{array}{c}\text { Tempo } \\
\text { (15 minutos) }\end{array}\end{array}$ & $\mathrm{G} 2$ & $\mathrm{G} 4$ & $\mathrm{G} 6$ \\
\hline
\end{tabular}

Fonte: Autor.

No Grupo 1 (G1), avaliou-se o fluido de corte sem contaminação. A contaminação dos Grupos 2, 3, 4, 5, 6 e 7 com Penicillium oxalicum foi dada utilizando 5 alçadas do fungo para cada amostra de fluido de corte de $100 \mathrm{~mL}$. Antes de iniciar os tratamentos, alíquota das amostras $(1 \mathrm{~mL})$ e suas diluições $\left(10^{-1}, 10^{-2}, 10^{-3}\right)$ ão adicionadas em placas de Petri, logo em seguida, verte-se, separadamente, $20 \mathrm{~mL}$ de Potato Dextrose Ágar, mantidos em banho-maria, a $45^{\circ} \mathrm{C}$, sobre cada placa, (método Pour Plate). Esse procedimento foi realizado antes e depois dos ensaios, em 
duplicata, a fim de obter uma comparação da eficiência do tratamento.

Como existe aquecimento durante o ensaio de ultrassom, e este aumento de temperatura não era desejado pela equipe, o recipiente com o fluido a ser tratado ficou em banho de gelo. $\mathrm{O}$ aquecimento do fluido de corte pode modificar as propriedades físico-químicas dos lubrificantes, favorecendo a degradação térmica e, assim, perdendo propriedade lubrificante. A fim de garantir a não contaminação das amostras, a ponteira do ultrassom foi autoclavada antes e depois dos ensaios.

\subsection{Contagem de UFCs e Avaliação da Eficiência do Tratamento}

A contagem total de bolores e leveduras foi realizada pelo método de contagem de placas padrão, realizada em duplicata, de acordo com a metodologia descrita por SILVA et al., 2010, adaptada, seguindo todos os protocolos de biossegurança preconizados, utilizando-se Potato Dextrose Ágar como meio de cultura, incubando-se a amostra à temperatura $22-25^{\circ} \mathrm{C}$, por 5 dias, para bolores e leveduras.

As placas que apresentaram crescimento de colônias fúngicas tiveram o valor das unidades formadoras de colônias (UFC) multiplicadas pelo valor da diluição da amostra utilizada, para corrigir a diluição feita. Após o crescimento das colônias e sua contagem, verificou-se que, após a adição do extrato em estudo, houve redução do número de unidades formadoras de colônias pela fórmula:

\section{$\mathrm{UFC} / \mathrm{mL}=\underline{\text { contagem inicial }- \text { contagem final } X 100}$ Contagem final}

\section{RESULTADOS E DISCUSSÃO}

A partir da triagem da atividade antimicrobiana do Safeteam em Candida sp. determinou-se a CIM de 5\%. De acordo com Lima et. al (2006), óleos essenciais apresentam efetividade de inibição pela formação de halos com diâmetro igual ou superior a $10 \mathrm{~mm}$. Porém, como o foco do estudo são os bolores, os ensaios seguiram com Penicillium oxalicum, gênero identificado em fluidos de corte do CCM e em diversos artigos. Os bolores se espalham e desenvolvem com maior facilidade porque sua reprodução é por esporulação, e grande parte desses fungos são ambientais.

\subsection{Tratamento Químico - Óleo essencial comercial Safeteam}

Foi observado que o Penicillium Oxalicum apresentou-se sensível frente formulação comercial do extrato vegetal estudado (Safeteam), quando utilizado em concentração $5 \%$. Houve uma redução de $100 \%$ das UFCs após a adição do extrato vegetal em fluido de corte contaminado com inóculo fúngico, conforme Figura 3. 
Figura 3: Avaliação do potencial fungicida do extrato vegetal Safeteam quando utilizado com concentração 5\% em Penicillium oxalicum.

Grupo 2: Controle positivo

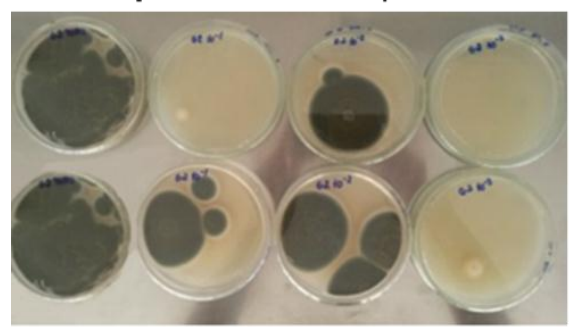

Grupo 3: Controle negativo

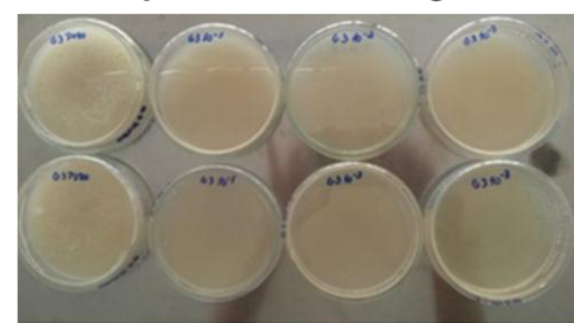

Grupo 4: Teste

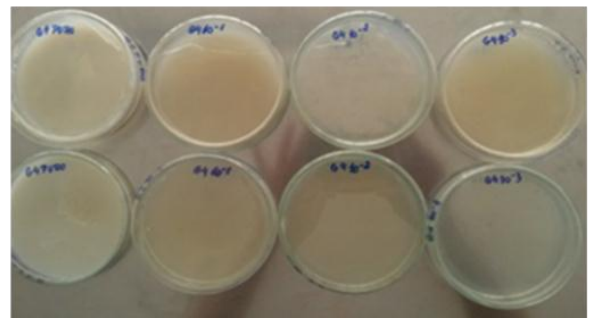

Fonte: Autor

$\mathrm{Na}$ tabela 2, é possível observar a contagem de UFCs para cada diluição feita, comparando os grupos: 2 (controle positivo), 3 (controle negativo) e 4 (teste).

Tabela 2: $\mathbf{C}+=$ controle positivo, $\mathrm{C}-\mathbf{=}$ controle negativo, UFC/mL= unidades formadoras de colônia por mililitros

\begin{tabular}{l|ccc}
\hline Diluições & Grupo 2 (C+) & Grupo 3 (C-) & Grupo 4 (teste) \\
\hline PURO & Incontável & $0 \mathrm{UFC} / \mathrm{mL}$ & $0 \mathrm{UFC} / \mathrm{MI}$ \\
PURO (2) & Incontável & $0 \mathrm{UFC} / \mathrm{mL}$ & $0 \mathrm{UFC} / \mathrm{MI}$ \\
$1: 10$ & $10 \mathrm{UFC} / \mathrm{mL}$ & $0 \mathrm{UFC} / \mathrm{mL}$ & $0 \mathrm{UFC} / \mathrm{mL}$ \\
$1: 10(2)$ & $30 \mathrm{UFC} / \mathrm{mL}$ & $0 \mathrm{UFC} / \mathrm{mL}$ & $0 \mathrm{UFC} / \mathrm{MI}$ \\
$1: 100$ & $200 \mathrm{UFC} / \mathrm{mL}$ & $0 \mathrm{UFC} / \mathrm{mL}$ & $0 \mathrm{UFC} / \mathrm{mL}$ \\
$1: 100(2)$ & $300 \mathrm{UFC} / \mathrm{mL}$ & $0 \mathrm{UFC} / \mathrm{mL}$ & $0 \mathrm{UFC} / \mathrm{mL}$ \\
$1: 1000$ & $0 \mathrm{UFC} / \mathrm{mL}$ & $0 \mathrm{UFC} / \mathrm{mL}$ & $0 \mathrm{UFC} / \mathrm{mL}$ \\
$1: 1000(2)$ & $1000 \mathrm{UFC} / \mathrm{mL}$ & $0 \mathrm{UFC} / \mathrm{mL}$ & $0 \mathrm{UFC} / \mathrm{mL}$ \\
& & & \\
\hline
\end{tabular}

\section{Fonte: Autor.}

Para o cálculo da porcentagem de redução do número de colônias, foi escolhida a diluição 1:100 que compreende de 30 a 300 colônias, dos grupos 2 e 4 . Primeiramente, somou-se o número de UFC de cada placa da diluição 1:100 do grupo 2, calculou-se a média aritmética e multiplicou-se pela diluição correspondente. Conforme as equações:

$$
U F C / m L \text { Grupo } 2=\frac{2+3 \times 100}{2}=250 U F C
$$




$$
\begin{gathered}
\text { \% de redução de } U F C / m L=\frac{C i-C f \times 100}{C i}=\frac{250-0 \times 100}{250}=100 \% \\
\qquad \mathrm{i} \text { = Contagem inicial, Cf = Contagem final. }
\end{gathered}
$$

De acordo com os resultados acima, o extrato vegetal Safeteam se mostrou eficiente no controle de contaminação fúngica em fluidos de corte, uma vez que reduziu o número de colônias para zero. Outra vantagem de se usar esse biocida natural é que, além de não deixar resíduos na natureza, não provoca a resistência bacteriana (CAETANO; MADALENO, 2011).

\subsection{Tratamento Físico - Ultrassom}

O método do ultrassom se mostrou eficiente no controle de contaminação fúngica; no entanto, o número de unidades formadoras de colônia não foi totalmente reduzido para zero. Por esse motivo, não foi possível realizar o cálculo da porcentagem de redução do número de colônias, no entanto, é possível visualizar o impacto positivo que esse método causou no controle da contaminação, de acordo com a tabela 3.

Tabela 3: Contagem de UFC antes e após 10 dias do tratamento de ultrassom no fluido de corte. $\mathrm{C}$ - = controle negativo, UFC/mL= unidades formadoras de colônia

\begin{tabular}{|c|c|c|c|c|c|c|c|}
\hline Diluições & $\begin{array}{c}\text { G1 } \\
\text { (Controle -) }\end{array}$ & $\begin{array}{c}\mathrm{G} 2(\mathrm{P}=100 \%, \\
\left.\mathrm{T}=30^{\prime}\right)\end{array}$ & $\begin{array}{c}\mathrm{G} 3(\mathrm{P}=100 \%, \\
\left.\mathrm{T}=15^{\prime}\right)\end{array}$ & $\begin{array}{c}\text { G4 }(P=75 \%, \\
\left.T=30^{\prime}\right)\end{array}$ & $\begin{array}{c}\mathrm{G} 5(\mathrm{P}=75 \% \\
\left.\mathrm{T}=15^{\prime}\right)\end{array}$ & $\begin{array}{c}\mathrm{G} 6(\mathrm{P}=50 \%, \\
\left.\mathrm{T}=30^{\prime}\right)\end{array}$ & $\begin{array}{c}\text { G7 }(P=50 \%, \\
\left.T=15^{\prime}\right)\end{array}$ \\
\hline $\begin{array}{l}\text { Todas } \\
\text { (antes) }\end{array}$ & $0 \mathrm{UFC} / \mathrm{mL}$ & Incontável & Incontável & Incontável & Incontável & Incontável & Incontável \\
\hline $\begin{array}{l}1: 10(1) \\
\text { depois }\end{array}$ & $0 \mathrm{UFC} / \mathrm{mL}$ & $0 \mathrm{UFC} / \mathrm{mL}$ & $50 \mathrm{UFC} / \mathrm{mL}$ & $0 \mathrm{UFC} / \mathrm{mL}$ & $10 \mathrm{UFC} / \mathrm{mL}$ & $10 \mathrm{UFC} / \mathrm{mL}$ & $30 \mathrm{UFC} / \mathrm{mL}$ \\
\hline $\begin{array}{l}1: 10(2) \\
\text { depois }\end{array}$ & $0 \mathrm{UFC} / \mathrm{mL}$ & $0 \mathrm{UFC} / \mathrm{mL}$ & $0 \mathrm{UFC} / \mathrm{mL}$ & $0 \mathrm{UFC} / \mathrm{mL}$ & $70 \mathrm{UFC} / \mathrm{mL}$ & $60 \mathrm{UFC} / \mathrm{mL}$ & $0 \mathrm{UFC} / \mathrm{mL}$ \\
\hline $\begin{array}{c}\text { 1:100 (1) } \\
\text { depois }\end{array}$ & $0 \mathrm{UFC} / \mathrm{mL}$ & $100 \mathrm{UFC} / \mathrm{mL}$ & $100 \mathrm{UFC} / \mathrm{mL}$ & $0 \mathrm{UFC} / \mathrm{mL}$ & $200 \mathrm{UFC} / \mathrm{mL}$ & $1200 \mathrm{UFC} / \mathrm{mL}$ & $300 \mathrm{UFC} / \mathrm{mL}$ \\
\hline $\begin{array}{c}\text { 1:100 (2) } \\
\text { depois }\end{array}$ & $0 \mathrm{UFC} / \mathrm{mL}$ & $1600 \mathrm{UFC} / \mathrm{mL}$ & $0 \mathrm{UFC} / \mathrm{mL}$ & $0 \mathrm{UFC} / \mathrm{mL}$ & $0 \mathrm{UFC} / \mathrm{mL}$ & $100 \mathrm{UFC} / \mathrm{mL}$ & $800 \mathrm{UFC} / \mathrm{mL}$ \\
\hline $\begin{array}{c}1: 1000(1) \\
\text { depois }\end{array}$ & $0 \mathrm{UFC} / \mathrm{mL}$ & $0 \mathrm{UFC} / \mathrm{mL}$ & $0 \mathrm{UFC} / \mathrm{mL}$ & $0 \mathrm{UFC} / \mathrm{mL}$ & $1000 \mathrm{UFC} / \mathrm{mL}$ & $12000 \mathrm{UFC} / \mathrm{mL}$ & $0 \mathrm{UFC} / \mathrm{mL}$ \\
\hline $\begin{array}{c}\text { 1:1000 (2) } \\
\text { depois }\end{array}$ & $0 \mathrm{UFC} / \mathrm{mL}$ & $3000 \mathrm{UFC} / \mathrm{mL}$ & $0 \mathrm{UFC} / \mathrm{mL}$ & $0 \mathrm{UFC} / \mathrm{mL}$ & $0 \mathrm{UFC} / \mathrm{mL}$ & $5000 \mathrm{UFC} / \mathrm{mL}$ & $0 \mathrm{UFC} / \mathrm{mL}$ \\
\hline
\end{tabular}
por mililitros.

Fonte: Autor.

Notou-se que, com a diminuição da potência e do tempo no tratamento, não ocorreram alterações significativas em relação à sobrevivência das colônias nos fluídos de corte tratados com ultrassom, necessitando avaliar mais parâmetros de potência, tempo e amplitude. Apesar do tratamento do fluido de corte por ultrassom não erradicar a contaminação, ele pode ser utilizado como um tratamento ao longo do uso do fluido de corte, fazendo um controle microbiológico. Favorecendo, assim, o retorno do fluido de corte tratado ao ciclo produtivo (em processos de usinagem), prolongando sua vida útil. 


\section{CONCLUSÃO}

Com os resultados obtidos, podemos observar que o produto em teste teve um desempenho satisfatório alcançando uma concentração inibitória mínima relativamente baixa $(5 \%)$ sobre os fungos. Com isso, o extrato vegetal se mostrou uma alternativa promissora para prolongar a vida útil dos fluidos de corte. No entanto, por ser novo no mercado, ainda faltam mais estudos sobre seus princípios ativos e a caracterização química desse extrato, para que haja um controle de contaminação fúngica, menores custos para as empresas e menos impacto ambiental de produtos químicos utilizados com essa finalidade. A taxa de Penicillium sp. diminuiu, significantemente, após o tratamento com ultrassom no fluido de corte contaminado, sendo eficiente em uma potência $(72 \mathrm{~W})$ e tempo baixos $(15 \mathrm{~min})$ de tratamento. $\mathrm{O}$ tratamento do ultrassom se mostrou um método com grande potencial a ser estudado para implantação no mercado, pois pode oferecer uma possível recuperação do fluido de corte para que este possa retornar aos processos de usinagem.

\section{AGRADECIMENTOS}

O presente artigo foi desenvolvido com a contribuição da equipe multidisciplinar, aporte estrutural e técnico da Universidade do Vale do Paraíba (UNIVAP), em parceria com o Centro de Competência em Manufatura do Instituto Tecnológico de Aeronáutica - CCM/ITA, além do subsídio financeiro do Conselho Nacional de Desenvolvimento Científico e Tecnológico - CNPq à empresa parceira de fluido de corte Houghton pela formulação e doação do produto sem biocida.

\section{DIREITOS AUTORAIS}

Os autores são os únicos responsáveis pelo conteúdo do material impresso incluídos no trabalho.

\section{REFERÊNCIAS}

BIANCHI et. al; Controle do crescimento microbiano nos fluídos de corte utilizando radiação ultravioleta. CIMM, Bauru: Departamento de Ciências Biológicas- UNESP, 2007.

CAETANO, A. C. G.; MADALENO, L. L. Controle de contaminantes bacterianos na fermentação alcoólica com a aplicação de biocidas naturais. Ciência e Tecnologia: FACTEC-JB, v. 2, n. 1, p. 27-37, 2011.

CALIARI, M; SOARES JÚNIOR, M. S.; GOMES, R. J. C. Efeito de ondas ultra-sônicas sobre a população de Leuconostoc mesenteroides em caldo de cana-de-açúcar.

Pesquisa Agropecuária Tropical, v. 34, n. 3, p. 139-143, 2004. 
CAPELLETTI, R. V. Avaliação da atividade de biocidas em biofilmes formados a partir de fluido de corte utilizado na usinagem de metais. 2006. Campinas, 81f. Dissertação (Mestrado em Engenharia Química) - Faculdade de engenharia Química, Campinas, 2006.

DOURADO, D. et. al. Óleos essenciais e suas atividades antimicrobianas: Prospecção Tecnológica. Cadernos de Prospecção (online), v. 7, n. 4, 2014.

DUARTE, M. C. T. Atividade Antimicrobiana de Plantas Medicinais e Aromáticas Utilizadas no Brasil. Universidade Estadual de Campinas- Centro de Pesquisas Químicas, Biológicas e Agrícolas. Outubro, 2006.

FREIRE, M. F. I.; MORRA, M. J.; KNUDSEN, G. R. Atividade antifúngica de substâncias voláteis presentes em Brassica napus sobre o crescimento micelial de Fusarium oxysporum. Laboratório de Fitossanidade; Instituto de Pesquisas Jardim Botânico do Rio de Janeiro, RJ. Rev. Bras. Farm., v. 84, n. 3, p. 97-99, 2003.

GOMES, J. D. O. et. al. Manual de gerenciamento de fluidos de corte. São José dos Campos: Instituto Tecnológico de Aeronáutica, 2005.

LIMA, I. O et. Al. Atividade antifúngica de óleos essenciais sobre espécies de Candida. Revista Brasileira de Farmacognosia, v. 16, n. 2, p. 197-201, 2006.

LUCCHESI, E. G. Desenvolvimento de sistema de obtenção de biofilmes in vitro e avaliação de sua susceptibilidade a biocidas. Campinas, $91 \mathrm{f}$. Dissertação (Mestrado em Biotecnologia) - Universidade Estadual de Campinas, Campinas, 2006.

MONSELL, A. El extracto de Semilla de Pomelo: Una alternativa natural a los antibióticos., 2009. Disponível em:

$<$ http://www.cienciainvisible.com/pomelo/semillapomelo.pdf > Acesso em: 08 mai. 2015.

NOVELLINE, R. Squire's. Fundamentals of Radiology. Harvard University Press. p. 34-35, 1997.

QUARESMA, T. C. Aplicação de ozônio e ultrassom na desinfecção das mãos de profissionais da saúde. 2013. São José dos Campos, 78f. Dissertação (Mestrado em Bioengenharia) - Universidade Camilo Castelo Branco. Instituto de Engenharia Biomédica, São José dos Campos, 2013.

SILVA, M. T. et. al., Controle do Desenvolvimento de Fungos em Fluídos de Corte na Usinagem. São José dos Campos: Universidade do Vale do Paraíba, NUFABI (Núcleo de Estudos - Farmacêuticos e Biomédicos) da Faculdade de Ciências da Saúde (FCS), 2014.

SILVA, N. et. al. Manual de métodos de análise microbiológica de alimentos. 2. ed. São Paulo: Livraria Varela, 2010, 229 p.

SILVA, J. P. L. Avaliação da ação de antimicrobianos naturais no controle de Salmonella enteritidis em salada de legumes com maionese. 2007. São Paulo, 90f. Tese (Doutorado em Ciências de Alimentos) - Universidade de São Paulo, São Paulo, 2007.

THOMÉ, R. et. al. Estudo microbiológico das microbactérias e fungos contaminantes dos fluídos de corte. CONGRESSO IBEROAMERICANO DE ENGENHARIA 
MECÂNICA, 8, Cusco, Peru, 2007. Anais..., Cusco, 2007. Disponível em:

<http://congreso.pucp.edu.pe/cibim8/pdf/24/24-28.pdf >. Acesso em: 07 nov. 2014. 